\title{
H1N1 Influenza: Global Pandemic, Global Vulnerabilities
}

\section{By Diego S. Silva}

Although the media glare has subsided, the H1N1 pandemic continues to have disproportionately higher rates of morbidity in persons of lower socioeconomic status (SES) relative to those of higher SES, requiring a global response rooted in solidarity. Decision-makers and the public, in both economically rich and poor countries, need to address the material and social inequalities that make certain populations particularly susceptible to severe cases of H1N1. Although the global prevalence of H1N1 is higher in young and healthy individuals, the morbidity and mortality caused by the virus disproportionately affects persons who suffer from chronic lung and cardiac diseases, diabetes, and obesity all risk factors more commonly found in persons of lower SES than in the general population. ${ }^{1}$

In middle-income countries such as Argentina and Peru, the risk factors associated with severe cases of H1N1 were comparable to those identified globally by the WHO., ${ }^{2,3}$ In South Africa, additional risk factors for severe cases of H1N1 included compromised immunity because of HIV/AIDS (53\% of influenza associated deaths) ${ }^{4}$ and active tuberculosis (10\% of influenza associated deaths), both diseases that are more prevalent in lower SES populations. However, these are merely three examples from middle-income countries; it is difficult to ascertain epidemiological data from lowincome countries due to a lack of surveillance capabilities. In the WHO African Region, for example, 12 of $46(26 \%)$ member countries had no official data to report from the $\mathrm{H} 1 \mathrm{~N} 1$ pandemic. ${ }^{5}$

The risk factors for severe illness due to H1N1 in high-income countries are also commonly found in persons of lower SES. In Canada and New Zealand for example, indigenous communities, which normally have a higher burden of disease than non-indigenous communities and are generally of lower SES, suffered the most severe effects of $\mathrm{H} 1 \mathrm{~N} 1^{6}$. In Canada, Kumar and colleagues found

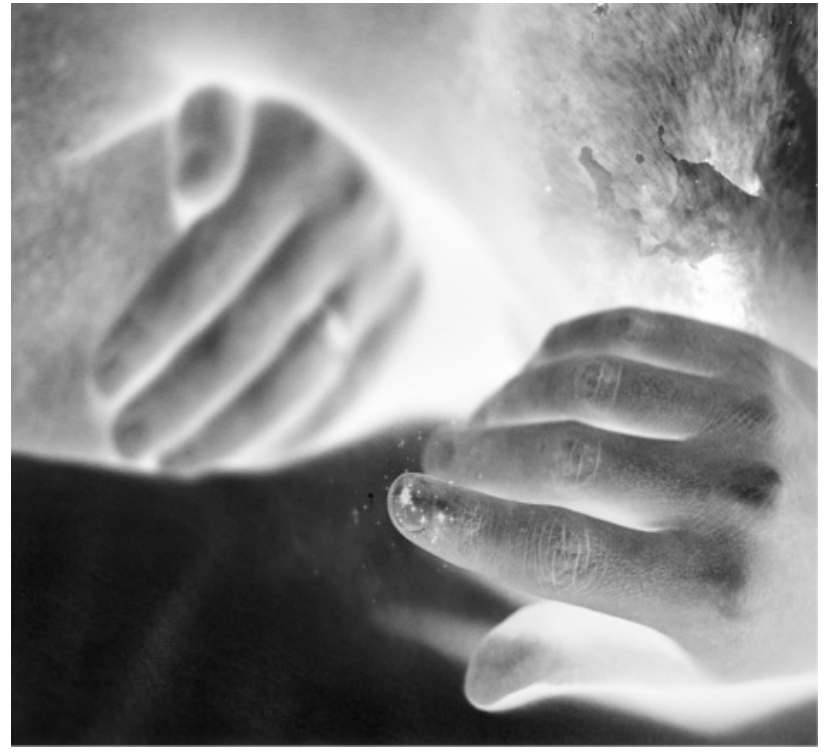

that $25.6 \%$ of confirmed or probable cases of critical illness caused by H1N1 occurred in Aboriginal persons. $^{7}$ Campbell and colleagues found the incidence of ICU admission in Aboriginals to be 4.08 per 100,000 persons, compared to 0.07 per 100,000 in the general Canadian population. ${ }^{8}$ Despite these rates of severe H1N1, Aboriginals only account for $3 \%$ of Canada's total population. ${ }^{9}$ Correlations may exist between the risk factors associated with severe H1N1 and the higher prevalence of cardiopulmonary diseases, diabetes, and obesity in indigenous populations.

The plight of persons of lower SES during the H1N1 pandemic requires the global community to acknowledge peoples' shared vulnerabilities. Practically, and perhaps selfishly, everyone should be concerned about a virus that can mutate easily and does not respect the jurisdiction of states. Not only do infectious diseases, like influenza, not respect borders, but we also need to recognize that inequalities in wealth and health lead to adverse social conditions (e.g. poor sanitation) that can breed resilient microorganisms (e.g. multi- and extensivedrug resistant tuberculosis). ${ }^{10}$ 
Addressing the morbidity and mortality caused by the H1N1 pandemic and future pandemics will require a spirit of solidarity between countries and persons of different SES. What does global solidarity entail in practice? First, we need to acknowledge that material (e.g. a lack of clean water) and political (e.g. a lack of education for women) disadvantages are at least as important as biological factors in determining the likelihood of becoming ill and the severity of a person's illness vis-à-vis infectious diseases. ${ }^{11,12}$ Second, we must develop healthcare policies that respond to emergencies in a manner that do not exacerbate existing inequities. For example, scarce resources (e.g. ventilated beds in intensive care units) should not be allocated solely on the basis of the likelihood of survival, since the ability of people to survive an infectious disease, like $\mathrm{H} 1 \mathrm{~N} 1$, is often positively correlated to contextual factors associated to SES (i.e. people of higher SES, who are more likely to survive ventilation, will be at an advantage if ventilators are allocated only on the basis of survivability). ${ }^{13}$ Finally, decision-makers need to dialogue with the general public, and in particular vulnerable persons, in order to make informed policy and practice decisions that are sensitive to contextual factors. ${ }^{14}$ Not only might dialogue ensure that decisions are sensitive to the varying realities of different populations, but it is also in keeping with the democratic spirit of most of the world's governments.

\section{Acknowledgements}

I would like to thank Dr. Sally Bean (Ethics Centre, Sunnybrook Health Sciences Centre, Toronto) and Dr. Ross Upshur (Department of Family and Community Medicine, Dalla Lana School of Public Health, and Joint Centre for Bioethics, University of Toronto) for their help and support in preparing this manuscript.

\section{References}

1. World Health Organization. Clinical management of human infection with pandemic (H1N1) 2009: revised guidance November 2009.

http://www.who.int/csr/resources/publications/swineflu/clinic al_management_h1n1.pdf (accessed March 30, 2010).

2. Bantar C, Oliva ME, Re HA, et al. Severe acute respiratory disease in the setting of an epidemic of swine-origin at a reference hospital in Entre Rios, Argentina. CID 2009;49:1458-60.
3. Gomez J, Munayco CV, Arrasco JC, et al. Pandemic influenza in a southern hemisphere setting: the experience in Peru from May to September, 2009. Euro Surveill 2009;14(42):pii=19371.

4. Archer $\mathrm{BN}$, Cohen $\mathrm{C}$, Naidoo $\mathrm{D}$, et al. Interim report on pandemic H1N1 influenza virus infections in South Africa, April to October 2009: epidemiology and factors associated with fatal cases. Euro Surveill 2009;14(42):pii=19369.

5. World Health Organization, African Region. Pandemic (H1N1) 2009 in African Region: Update 76. http://www .afro. who.int/index.php?Itemid=2544 (accessed March 30, 2010).

6. La Ruche G, Tarantola A, Barboza P, et al. The 2009 pandemic H1N1 influenza and indigenous populations of the Americas and the Pacific. Euro Surveill 2009;14(42):pii=19366.

7. Kumar A, Zarychanski R, Pinto R, et al. Critically ill patients with 2009 influenza $\mathrm{A}(\mathrm{H} 1 \mathrm{~N} 1)$ infection in Canada. JAMA 2009;302(17):1872-1979.

8. Campbell A, Rodin R, Kropp R, et al. Risk of severe outcomes among patients admitted to hospital with pandemic (H1N1) influenza. CMAJ 2010;182(4):349-355.

9. Statistics Canada. Aboriginal identity population, 2001 counts for Canada, Provinces and Territories. http://www12.statcan.ca/english/census01/products/highlight/ Aboriginal $/$ Page. $\mathrm{cfm}$ ?Lang $=\mathrm{E} \& \mathrm{Geo}=\mathrm{PR} \& \mathrm{View}=1 \mathrm{a} \&$ Table $=$ $1 \&$ StartRec $=1 \&$ Sort $=2 \& \mathrm{~B} 1=$ Counts01\&B2=Total $($ accessed March 30, 2010).

10. Battin MP, Francis LP, Jacobson JA, et al. The Patient as Victim and Vector: Ethics and Infectious Diseases. New York: Oxford University Press; 2008.

11. Mastroianni AC. Slipping through the net: social vulnerability in pandemic planning. Hasting Cent Rep 2009;39(5):11-12

12. Smith MJ, Bernard C, Rossiter $\mathrm{K}$, et al. Letter Vulnerability: a contentious and fluid term. Hasting Cent Rep 2010;40(1):4-6.

13. Silva DS, Nie JX, Rossiter K, et al. Contextualizing ethics: ventilators, H1N1 and marginalized populations. Healthc Q 2010;13(1):32-36.

14. Canadian Program of Research on Ethics in a Pandemic. Ethics and pandemic influenza: white paper series. University of Toronto Joint Centre for Bioethics, 2009. http://www.canprep.ca/CanPREP_WP_Series.pdf (accessed March 30, 2010).

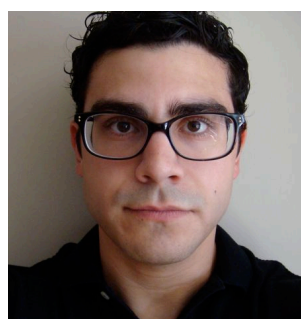

Author Profile

Diego Silva is currently purusing a $\mathrm{PhD}$ degree in Health Behaviour Science at the Dalla Lana School of Public Health at the University of Toronto. His main research interests are in public health and mental health ethics, which allows him to work in conjunction with the Collaborative Program in Bioethics (Joint Centre for Bioethics) at the University of Toronto. Previously, Diego had received a MA degree in philosophy from the University of Toronto. 